\title{
Commission 46: Program Group for the World-Wide Development of Astronomy
}

\author{
CHAIRPERSON: John Hearnshaw \\ ORGANIZING COMMITTEE: Don Wentzel (USA) Alan Batten \\ (Canada) Hakim Malasan (Indonesia) Jay White (USA) Mary Kay \\ Hemenway (USA) Yoshihide Kozai (Japan) Athem Alsabti \\ (UK/Iraq) Peter Martinez (South Africa) Richard Gray (USA) \\ Jayant Narlikar (India) Julieta Fierro (Mexico) Hugo Levato
}

(Argentina) (from Sept. 2003)

\section{Introduction}

The Program Group for the World-wide Development of Astronomy (PGWWDA) is one of nine Comm. 46 program groups engaged with various aspects of astronomical education or development of astronomy education and research in the developing world. In the case of PGWWDA, its goals are to promote astronomy education and research in the developing world through a variety of activities, including visiting astronomers in developing countries and interacting with them by way of giving encouragement and support.

\section{Aims and objectives of PGWWDA}

The principal aims and objectives of PGWWDA are: (a) To visit developing countries (often IAU non-member states) with some limited astronomical expertise, and which would welcome some development of their capabilities in astronomy; (b) To give encouragement, and to explore the possible assistance of the IAU in developing astronomy in these countries; (c) To discuss with astronomers in developing countries the available resources for astronomical teaching or research, and to promote international contacts and exchanges between astronomers in these countries and those elsewhere; (d) To write reports on the state of astronomy in developing countries for the Commission 46 president and to send these reports to the IAU Executive Committee; (e) If the conditions were deemed favorable, then to follow-up any report with involvement by TAD or other program groups of Comm. 46, as may be appropriate.

\section{Visit to Mongolia}

John Hearnshaw spent a week in Mongolia from 11-18 March 2004 on behalf of PGWWDA. His visit was hosted by Prof G. Batsukh in the Geophysics department of the National University of Mongolia (NUM) in Ulaanbaatar. Four academics in this department were teaching undergraduate astronomy. Further astronomers were employed by the Mongolian Technical University as well as by the Mongolian Academy of Sciences at the Research Center of Astronomy and Geophysics (RCAG) and the associated Khurel Togoot Observatory, both being part of the Academy. Visits were made to the observatory and to the Academy, where a meeting with Dr T. Galbaatar, the Acting President of 
the Mongolian Academy of Sciences, took place on 17 March. About a dozen astronomers are employed in Mongolian universities or at RCAG, and they would benefit greatly if Mongolia were to adhere to the IAU. A subsequent application for membership resulted from these discussions. A series of four lectures was presented at NUM by Hearnshaw during this visit.

\section{Visit to Kenya}

Peter Martinez (South African Astronomical Observatory) made a visit to Kenya 15-17 June 2004. His visit was hosted by the Physics Department of the University of Nairobi, where Dr Paul Baki is an active astronomer teaching in the department. Four other academics in the department have some interests in astronomy. Work and advice on an undergraduate astronomy syllabus was undertaken during this visit and Dr Martinez gave a series of lectures. Plans for Kenya to acquire a small telescope (about aperture $0.5 \mathrm{~m}$ ) were discussed and it was proposed that Dr Baki be nominated for individual membership of the IAU. Dr Baki has been invited to make a presentation at the Special Session \#5 Astronomy for the developing world at the 26th General Assembly in Prague.

\section{Contact with Thai astronomers}

John Hearnshaw has maintained contact with Thai astronomers, notably at Chiang Mai University (CMU) in northern Thailand. This has partly been through a Thai astronomy $\mathrm{PhD}$ student he is supervising in New Zealand, but also through Boonrucksar Soonthornthum, a Thai astronomer who was formerly an MSc student in New Zealand. Boonrucksar was until 2005 Dean of Science at CMU. He is now Director of the new Thai National Astronomical Research Institute (NARI). He visited New Zealand to meet with this writer in September 2005.

There is substantial astronomical activity in Thailand, both at CMU and at least five other Thai universities. At NARI a 2.5-m telescope should be installed on Inthanon, Thailands highest mountain near Chiang Mai, by late 2007 or 2008. Thailand had considered joining the IAU a few years ago, but without a successful outcome. The decision to found and equip NARI with substantial capital expenditure has now made a re-consideration of this proposal very favorable, and a new application by Thailand to join the IAU in 2006 has been made. This is a logical decision, as of all the IAU non-member countries in the world, Thailand probably has more professional astronomical activity than any other.

Hearnshaw has tentative plans to visit CMU and NARI in late 2006 or early 2007.

\section{Visit to Iraq}

Athem Alsabti, a member of PGWWDA, visited Iraq in April 2004 to investigate the state of astronomy in that country and to explore the possibility of rehabilitating the Mt Korek Observatory in northern Iraq, which had been damaged in the Iran-Iraq war in 1989, before becoming operational. A 3.5-m Zeiss telescope had been installed there, as well as a $1.25-\mathrm{m} \mathrm{RC}$ reflector, and a $30-\mathrm{m}$ radio telescope for $\mathrm{mm}$ wavelengths.

His visit took him to Baghdad University, the Ministry of Higher Education in Baghdad, the Iraqi National Academy of Science, Salahaddin University in Erbil in Kurdish Iraq and then to Mt Korek. He met with vice-chancellors of most Iraqi universities while in Baghdad. 
Dr Alsabti reported after this visit that: There is a very strong support from the Kurdish scientists and authorities (a) to rebuild the Observatory and (b) to start astronomical studies in the Kurdish region based at Erbil.

\section{Visit to Cuba}

John Hearnshaw and Julieta Fierro visited Cuba for a week in January 2005 on behalf of PGWWDA. The visit was hosted by the Instituto de Geofsica y Astronoma (IGA) in Havana. IGA is a part of the Ministry of Science, Technology and the Environment (CITMA). During our time there we had discussions with Dr Lourdes Palacio Surez and Prof. Jorge Prez Doval at IGA. They are respectively director of IGA and head of the astronomy section of IGA. We also had meetings with Dr Lilliam lvarez Daz, Director of of sciences at CITMA and with Dr. Oscar lvarez (CITMA), astronomer, attached as specialist in science in that ministry. Between us we presented seven talks, seminars or public lectures, all in different venues, and J. Fierro gave a television interview. We visited all the astronomical facilities of IGA, including Arroyo Naranjo Observatory and 60-cm Cassegrain telescope (in outskirts of Havana) and the Cacahual solar observatory with its solar telescope and spectrograph.

Cuba is an interim member of the IAU, but since the break-up of the Soviet Union its astronomers have been very isolated by political events and it was clear that astronomy is not a high priority for the present Cuban government. Nevertheless there are a few contacts between Cuban astronomers and those in developed countries. One Cuban astronomer is doing a $\mathrm{PhD}$ in Spain in observational astronomy and theoretical cosmologists (led by Dr Rolando Crdenas Ortiz) from the University Central de Las Villas, Santa Clara, in central Cuba have contacts with those in the U.K. We discussed ways of improving international contacts between astronomers in Cuba and those in the international community.

\section{Visit to Trinidad and Tobago}

John Hearnshaw visited the St Augustine campus of the University of the West Indies (UWI) in Trinidad and Tobago for a week in December 2005. His host was Dr Shirin Haque, an astronomer who is the acting head of the Physics Department of UWI. Although she is the only professional astronomer in Trinidad, she heads a small group of active students in the department, and she has established an organization called CARINA (the Caribbean Institute of Astronomy) whose aim is to promote the development of astronomy in the Caribbean region.

During the week in Trinidad, Hearnshaw gave three lectures or seminars, met with astronomy graduate students, visited the National Science Centre, gave radio and television interviews, visited the Trinidad and Tobago Astronomical Society and its observatory, and visited a private observatory on the island of Tobago to which UWI astronomers have regular access. As a result of this visit, Dr Haque, who was trained in astronomy at the University of Virginia in the US, has been nominated for individual membership of the IAU. Trinidad and Tobago does not adhere to the IAU. Such a step could come at a later date, if astronomical activity continues to grow at UWI, as is hoped.

\section{Future plans for PGWWDA}

PGWWDA has had a successful three years since we last met in person at the Sydney General Assembly. We have made contacts with astronomers in a number of developing 
countries, and as a result of these contacts follow-up work is in progress in many of these places.

We note that of these non-adhering countries, the Peoples Democratic Republic of Korea has 20 IAU individual members who are virtually isolated politically and hence also scientifically from the rest of the world. In addition there are seven IAU members in Kazakstan. Neither of these countries adheres to the Union, and both must be future places where PGWWDA might fruitfully explore contacts.

The highlights for the last three years must be the success in bringing both Mongolia and Thailand to the point of making applications to join the IAU as adhering countries. Significant pockets of astronomers were operating in isolation in both these places.

In the future, apart from North Korea and Kazakstan mentioned above, we see Colombia (which is a non-member country) as another important place to visit. We are also looking at Jordan, Uzbekistan, Mauritius, Laos, and perhaps several other countries in Latin America, Africa and south-east Asia. We feel it is productive to concentrate on helping countries where a few astronomers are already active and need to make contacts with the international community to grow further.

Often, as in Iraq, the current political situation prevents any major continuing efforts on the ground by PGWWDA, and the same is true in North Korea. However we note that 19 non-adhering countries have one or more IAU members with presumably few international contacts, a further approximately 20 developing countries do adhere to the union, but the astronomers resident in them still have limited access to international science, and some 115 countries essentially have no professional astronomical activity at all. In these circumstances it is clear that PGWWDA has plenty of work to do to help astronomers, no matter where they live, to participate in the global international scientific community. 